\title{
Measurement and analysis of small pelagic fish condition: A suitable method for rapid evaluation in the field
}

\author{
Brosset Pablo ${ }^{1,2, *}$, Fromentin Jean-Marc ${ }^{2}$, Ménard Frederic ${ }^{3}$, Pernet Fabrice ${ }^{4}$, \\ Bourdeix Jean-Herve ${ }^{2}$, Bigot Jean-Louis ${ }^{2}$, Van Beveren Elisabeth ${ }^{2}$, Pérez Roda Maria A. ${ }^{2}$, \\ Choy Sandrine ${ }^{3}$, Saraux Claire ${ }^{2}$
}

\footnotetext{
${ }^{1}$ Université Montpellier II, UMR 212 Ecosystèmes Marins Exploités, EME, Avenue Jean Monnet, CS 30171, 34203 Sète cedex, France

${ }^{2}$ IFREMER, UMR 212 EME, Avenue Jean Monnet, CS 30171, 34203 Sète cedex, France

${ }^{3}$ IRD, UMR 212 EME, Avenue Jean Monnet, CS 30171, 34203 Sète cedex, France

${ }^{4}$ IFREMER, Laboratoire des sciences de I'Environnement Marin, LEMAR, Technopole Brest Iroise, BP 70, 29280 Plouzané, France

* Corresponding author : Pablo Brosset, tel.: + 33499573214 ;

email address : pablo.brosset@ifremer.fr
}

\begin{abstract}
:
As condition is a key variable in population dynamics (especially for survival, growth and reproduction), the use of well-defined and accurate fish condition indices is capital. In particular, condition indices (morphometric, bioenergetic and biochemical) have never been compared and validated for the European anchovy Engraulis encrasicolus, the European pilchard Sardina pilchardus and the European sprat Sprattus sprattus. The accuracy of two indirect methods, the morphometric relative condition index $\mathrm{Kn}$ and the bioenergetics index determined with the Distell Fish Fatmeter was investigated by comparing with a direct measure of relative lipid content carried out with a thin layer chromatographyflame ionization detector. Estimations from the fatmeter correlated quite well with the relative lipid contents of all species, regardless of the reproductive period ( $R 2=0.69$ for anchovy, $R 2=0.75$ for sprat and $\mathrm{R} 2=0.48$ for sardine). Kn correlated more poorly with relative lipid content $(\mathrm{R} 2=0.22$ for anchovy and $\mathrm{R} 2=0.41$ for sardine, ns for sprat), especially during the reproductive period, pointing out the difficulty for such an index to precisely reflect changes in fat allocation. During the reproductive period, changes in Kn could reflect other processes, such as changes in protein content. Therefore, these different types of commonly used indices do not reflect exactly the same type of energy stores. The high repeatability of the fatmeter was brought to light, so that only one measurement on each fish side may be necessary to evaluate the relative lipid content of a small pelagic fish. Finally, fatmeter measurements were not affected by freezing storage up to one month for anchovy $(\mathrm{R} 2=0.66)$ and sardine $(R 2=0.90)$, making it possible to use frozen samples of both commercial and scientific survey. In contrast, the freezing storage for sprat should be avoided. Based on this study, the Fatmeter appears to be a suitable indirect method to assess condition and fat content of sardine and anchovy on a large number of individuals.
\end{abstract}




\section{Highlights}

Three body condition indices were compared in three small pelagic fish species. Bioenergetic index (fatmeter) correlated well with biochemical lipid estimation. The morphometric index appears more integrative and reflects more than just lipids. Fatmeter repeatability was high and frozen storage did not affect its measurements. - The fatmeter allows the quick and accurate tracking of the lipid of small pelagic fish.

Keywords : Anchovy, Fatmeter, Lipids, Mediterranean Sea, Sardine, Sprat 


\section{Introduction}

Body condition is a key variable widely used in ecological studies particularly on fish, mammals and birds to define the nutritional or the physiological status of an individual (Bolger and Connolly, 1989; Stevenson and Woods, 2006). Commonly, body condition is defined as the quantity of nutrient reserves, which represents the quantity of metabolizable tissues exceeding those required for daily nutritional demands (Schamber et al., 2009; Schulte-Hostedde et al., 2001). Body condition indices thus inform on the quantity of energy extracted from the environment and can give for instance important insights on foraging behavior or prey distribution (Lloret et al., 2013). They are also used as indicators of an individual's well-being which can affect its future performances (Stevenson and Woods, 2006; Wilson and Nussey, 2010). For example, individuals with larger nutritional reserves may have a greater survival rate, a larger reproductive success and a higher growth rate (Millar and Hickling, 1990), ultimately resulting in a link between body condition and fitness for several species (Jakob et al., 1996). Measuring body condition is thus of the outmost importance for physiologists and ecologists to understand population dynamics (SchulteHostedde et al., 2005) and monitor the status of fish stock (Lambert and Dutil, 1997).

A large number of condition indices are available from literature. They can be sorted in three categories, namely, morphometric, bioenergetic and biochemical indices. While some studies demonstrated a correlation between bioenergetic (measure of the relative amount of fat in one fat depot, mainly in muscles) and biochemical indices (Nielsen et al., 2005; Trudel et al., 2005; Vogt et al., 2002) or between biochemical and morphometric indices (Brown and Murphy, 2004; Pangle and Sutton, 2005), the use of three types of indices differs in terms of both methodology and meaning of the term condition. Morphometric indices are indirect and based on the assumption that for a given size, heavier individuals are in a better condition (Green, 2001). These indices assume that the bulk of available energy reserves is located in somatic and germ tissues, and then that the total weight is a suitable reflection of condition. They are extensively used because of their simplicity and have often been selected to monitor fish health (Lambert and Dutil, 1997), investigate the effect of marine pollution (Bervoets and Blust, 2003) or manage fisheries (Cone, 1989). Direct estimations of fish condition can also be determined through lipid content, protein or ash quantification (Stevenson and Woods, 2006). As lipids are the first component of energy reserves to be mobilized (McCue, 2010), the majority of studies using direct estimations relies on them, but because of the complexity and the diversity of energy stores, proteins might also be crucial, especially when lipids concentrations are very low. Biochemical lipid quantification methods are time-consuming and expensive, leading to a preferential use of morphometric indices over biochemical ones (Cone, 1989; Schamber et al., 2009). Finally, bioenergetics indices appear as a compromise between morphological and biochemical indices. They estimate lipid content through indirect measurements, e.g water content can be measured as it is strongly and inversely related to fat content (Craig et al., 1978; Simat and Bogdanović, 2012), as is done by the fatmeter (Distell Fish Fatmeter; Kent, 1990). This electronic device provides some advantages because it is easy to use, portable, fast and non-destructive, allowing researchers to keep the individual alive or intact for further analyses. While several authors recommended validating indirect indices against direct measurements of condition, only few studies have investigated the accuracy of indirect indices for fish. When these validations were realized, significant relationships between biochemical and morphometric indices were sometimes missing (McPherson et al., 2011; Nielsen et al., 2005), pointing out that morphometric condition indices were not always indicative of energy reserves. 
The aim of this study was firstly to compare three types of indices (morphometric, biochemical and bioenergetics) to understand the different information they provide. Comparative studies that involved three different types of condition indices are rare in literature and focused mostly on herring (Davidson and Marshall, 2010; McPherson et al., 2011). The second aim was to determine a reliable method, easy and quick enough to monitor body condition of small pelagic fish at the population scale (i.e allowing rapid measurements of a large number of individuals).

In this study, for the first time, the use of an electronic instrument that makes non-invasive measurements of water content to determine the relative lipid content of fish (Distell Fish fatmeter MFM-992 (Kent, 1990)) was investigated for three widespread small pelagic fish species namely the European pilchard Sardina pilchardus (Walbaum 1792), the European anchovy Engraulis encrasicolus (L. 1758) and the sprat Sprattus sprattus (L. 1758). They are the most significant species of the Gulf of Lions in terms of biomass and economic value. Up until recently, the estimation of relative lipid content by a fatmeter was done on medium and large species such as Atlantic herring Clupea harengus (L. 1758), eel Anguilla anguilla (L. 1758) and carp Cyprinus carpio (L. 1758) (Davidson and Marshall, 2010; Klefoth et al., 2013; McPherson et al., 2011). However, the apparition of a new model aiming at smaller fish opened new perspectives on species which could not be monitored before.

In order to know if indirect condition indices reflect lipid storage, the fatmeter and a common morphometric index, the relative condition were compared with biochemical analyzes of lipid content realized with a thin layer chromatography, a direct method considered here as a benchmark. Furthermore, only one study has ever investigated the effects of storage duration on fatmeter measurements (herring, Vogt et al., 2002). Here, various freezing durations were compared to determine precisely when differences were induced on fatmeter measurements. Moreover, the number of replications necessary to obtain reliable estimations of relative lipid content was explored for the first time using repeatability analyses.

\section{Material and methods}

\subsection{Study area and fish sampling}

In the Gulf of Lions $\left(42^{\circ} 26^{\prime}-43^{\circ} 12^{\prime} \mathrm{N}\right.$ and $\left.3^{\circ} 09-5^{\circ} 27 \mathrm{E}\right)$, a total of 499 anchovies, 488 sardines and 187 sprats were sampled from January 2013 to February 2014. June and July samples came from a standardized acoustic survey (PELMED) onboard the RV L'Europe", while the other samples were collected by commercial pelagic trawlers. For each sampling event, the same protocol was used, i.e. fish were randomly selected and measured directly onboard (scientific surveys) or one day after, in which case they were stored in ice (commercial fishing). For each fish, the total length (TL, to the nearest $1 \mathrm{~mm})$, total wet weight $(\mathrm{W}$, to the nearest $1 \mathrm{~g}$ ), sex, maturity stage (based on macroscopic observation of the gonads) and fat content (with Distell Fish fatmeter) were recorded. The usual five maturity stages were also estimated (ICES, 2008): a first stage during which gonads are inactive, two intermediate stages during which they are active, a fourth stage corresponding to the spawning event and a fifth stage during which the gonads are inactive and recovering.

\subsection{Morphometric index}

As the three species exhibited an allometric growth pattern (Beveren et al., 2014), the relative condition index $K_{n}$ (Le Cren, 1951) was used as a proxy of individual fish condition 
(Green, 2001). Indeed, $K_{n}$ prevents from the assumption of isometric growth and avoid a potential length effect. The index $K_{n}$ was computed as

$K_{n}=W / W_{r}$

where $W$ is the mass of an individual and $W_{r}$ is the theoretical mass of an individual of a given total length $(T L$ in $\mathrm{mm})$ predicted by a length-weight relationships $\left(W_{r}=\alpha . T L^{\beta}\right)$. Lengthweight relationships were calculated based on a 30-year dataset including more than 42,000 individuals and were characterized by $\alpha=0.0029 \pm 0.0001$ and $\beta=3.302 \pm 0.007$ for anchovy, $\alpha=0.0038 \pm 0.0001$ and $\beta=3.241 \pm 0.011$ for sardine, and $\alpha=0.0063 \pm 0.0005$ and $\beta=3.022 \pm 0.003$ for sprat.

\subsection{Bioenergetic index (Distell fish fatmeter)}

Based on the strong inverse relationship between water and fat content in fish (Craig et al., 1978; Simat and Bogdanović, 2012), the microstrip sensor (microwave) of the fatmeter estimates the relative fat content (\% lipids) of an individual from a permittivity calculation (Kent et al., 1992). The MFM-992 fatmeter used in this study was equipped with a small sensor head ( 3 centimeters wide), making it more adapted to analyze small fish. For each species the calibration provided by the manufacturer was used (sardine2, anchovy2 and sprat2). Relative lipid content was measured twice on the same location on both sides of the fish (along the lateral line as recommended in user manual) and the average of these four measurements was used as the final value. Even if temperature does not affect fatmeter measurements (Klefoth et al., 2013), all measurements were made following the same experimental conditions to avoid any potential bias.

\subsection{Repeatability of fatmeter measurements}

Repeatability was assessed by testing the similarity between different fatmeter measurements (reliability of measurement). In addition, the number of measurements required to obtain an accurate estimate was determined (Lessells and Boag, 1987). Among all fish available and independently of the subsample for lipid analysis, a random sub-sample of 73 anchovies, 54 sardines and 50 sprats was taken, on which four measurements were made on both sides of each individual $\left(n_{0}=8\right)$. Repeatability $(r)$ was computed from the results of an ANOVA as:

$$
\mathrm{r}=\frac{\mathrm{s}_{\mathrm{A}}^{2}}{\left(\mathrm{~s}^{2}+\mathrm{s}_{\mathrm{A}}{ }_{\mathrm{A}}\right)}
$$

where $\mathrm{s}^{2}$ is the within-group variance component $\left(M S_{W}\right)$ and $\mathrm{s}^{2}{ }_{\mathrm{A}}$ is the among-group variance component based on the mean square among groups $\left(\mathrm{MS}_{A}\right)$ and the mean square within groups $\left(M S_{W}\right)$ such as $s_{A}^{2}=\left(M S_{A}-M S_{W}\right) / n_{0}$. Here, one group is equivalent to one individual, so all eight measurements. Repeatability values vary between 0 and 1 , with a higher value indicating a better repeatability. To evaluate if the repeatability of the fatmeter measurements is size dependent, calculations were also performed per size class. The following classes were considered: small $(T L<105 \mathrm{~mm})$, small intermediate $(105 \leq T L<115$ $\mathrm{mm})$, large intermediate $(115 \leq \mathrm{TL}<125 \mathrm{~mm})$ and large $(T L \geq 125 \mathrm{~mm})$.

\subsection{Freezing impact on fatmeter measurements}

Freezing can lead to water loss in fish tissues. For example, for Atlantic salmon, Salmo salar L. 1758, this effect has been documented and the water loss was quantified as ranging from 
$0.5 \%$ to $5 \%$ of the initial individual's mass (Campañone et al., 2001; Regost et al., 2004). Therefore, freezing duration could influence fatmeter measurements. This effect was tested by comparing measurements on fresh individuals and on the same individuals after freezing at $-21^{\circ} \mathrm{C}$. Two freezing durations were considered: 5 and 31 days, using a sub-sample of 42 anchovies, 42 sardines and 42 sprats.

\subsection{Chemical analyses of lipids}

Immediately after morphometric and fatmeter measurements, a piece of muscle was removed from a sub-sample of 175 fish (60 anchovies, 60 sardines and 55 sprats). As lipids can be allocated both in the muscle and gonads during the reproductive period, gonads were sampled in addition to a piece of muscle for fish sampled in the reproductive period (i.e. 24 anchovies during summer and 30 sprats and 29 sardines during winter) to evaluate the link between fatmeter and total lipid content when a part of lipids is in gonads. The total weight of muscle and gonad of the fish was used to evaluate the relative part of each organ allowing to sum up their relative lipid content. Because in these three species of clupeids the weight of the liver and the stomach was too small in comparison to the other organs $(<1 \%)$, they were not taken into account. Relative lipid content was thus estimated as follows: Lipid $\%=$ (Muscle Weight * Muscle lipid \% + Gonad Weight * Gonad lipid \% / Fish Weight). Outside the reproductive period, gonad weight was so small that the formula simplified in Lipid $\%=$ Muscle lipid \%. Lipids were extracted from roughly $0.1 \mathrm{~g}$ of each sampled tissue using a solvent mixture (chloroform-methanol 2:1, v/v) as described by Folch et al., (1957). Then, lipid extracts were spotted to SIII Chromarods (latron laboratories) using a $10 \mu$ l Hamilton airtight glass syringe, and lipid classes were separated in a stepwise procedure using developing solvents of increasing polarity (Parrish, 1999). This method separates aliphatic hydrocarbons, sterol and wax esters, ketones, triacylglycerols, free fatty acids, free fatty alcohols, free sterols, diacylglycerols, acetone mobile polar lipids and phospholipids. Between each development, the Chromarods were partially scanned by flame ionization detection (FID) on an latroscan MK-VI (latron Laboratories). Chromatograms were analysed using integration software (Peak Simple version 3.29, SRI). Lipid classes were quantified using standard calibration curves obtained for each lipid class. Only one replicate was made according to the high repeatability of the latroscan (Choy, pers comm) and all experiments were made by the same person. The proportion of Free Fatty Acids (FFA) was checked to make sure it was not too high $(<1 \%)$ and lipids had not been degraded due to bad conservation. For the purpose of this study, only total lipid content obtained by summation of individual lipid classes is presented.

\subsection{Statistical analyses}

Influences of sex and maturity stages on the relationship between condition indices were investigated per species with a covariance analysis (ANCOVA) including interactions. This was based on the full dataset and after having tested for the assumption of normality. As all species had a significant effect of maturity stages on the relationship between the relative condition index and latroscan values, additional analyses were performed by grouping maturity stages 1 and 5 as representative of resting period and maturity stages 2 to 4 as prespawning and spawning periods. This partition allowed us to take into account inactive versus active gonads.

We conducted linear regression analyses between biochemical estimations of relative lipid content and both fatmeter and $\mathrm{K}_{\mathrm{n}}$ values. The coefficient of determination $\left(r^{2}\right)$ was used to estimate the proportion of variability explained and the strength of the relationship between the different variables tested. Similarly, linear regression was also carried out per species on the fatmeter values before and after the freezing procedure to determine the relationship 
between relative lipid content as estimated on fresh fish and on fish having undergone freezing. Furthermore, an ANCOVA was performed to evaluate the potential difference between the regression slopes of the two different freezing durations. To confirm that for linear regression the underlying statistical assumptions were not violated, normality of residuals was assessed by plotting theoretical quantiles versus standardized residuals $(Q-Q$ plots), and homogeneity of variance was evaluated by plotting residual versus fitted values. Analyses were performed with the statistical open source $R$ software ( $R$ Development Core Team, 2013). Values are indicated as mean \pm standard error (SE) and all statistical tests were performed at a significance level of 0.05 .

\section{Results}

\subsection{Relation between $K n$ and fatmeter values}

Size and condition indices of the three species were summarized in Table I. Interactions (e.g. between fatmeter and sex, fatmeter and maturity and sex and maturity) were not significant (ANCOVA, all $P>0.05$ ), highlighting no effect of sex and maturity on the relationship between the two indirect indices. Considering all individuals, the relative condition index $K_{n}$ was positively correlated with the fatmeter values for all three species (ANCOVA, all $P$ $<0.001$, respectively $F_{1,499}=64.26$ for anchovy, $F_{1,488}=374.34$ for sardine and $F_{1,187}=43.04$ for sprat, Fig. 1). However, $R^{2}$ values were low for sprat and anchovy (linear model, $R^{2}=0.27$ and 0.08 , respectively), while it was higher for sardine (linear model, $R^{2}=0.44$ ). At the same time, maturity stage showed a significant effect on the relative condition index $K_{n}$ for all 3 species (ANOVA, all $P<0.001, F_{5,499}=55.768 ; F_{5,488}=22.425$ and $F_{5,187}=14.786$, for anchovy, sardine and sprat, respectively). The higher the maturity stage, the higher the relative condition index for anchovy, while was the opposite for sardine and sprat. Conversely, sex had no significant effect (ANOVA, $P>0.05$ ).

\subsection{Comparison with biochemical analyses}

The sex did not show any significant effect on the relationships between biochemical index and fatmeter values or relative lipid content. Similarly, regardless of the species considered (ANCOVA, all $P>0.05$ ). The relationship between biochemical index and fatmeter was not significantly affected by maturity stages for any of the three species (ANCOVA, all $P>0.05$ ). Relative lipid contents evaluated by means of fatmeter and biochemical index were positively and highly correlated for all species (linear model, all $P<0.001$, respectively $n=60, R^{2}=0.69$ for anchovy; $\mathrm{n}=60, R^{2}=0.48$ for sardine and $\mathrm{n}=55, R^{2}=0.75$ for sprat) (Fig. 2 ).

On the contrary, the ANCOVA pointed out that maturity stages had a significant effect on the relationship between the biochemical index values and the relative condition index (respectively, $F_{5,48}=13.17, P<0.001$ for anchovy; $F_{5,47}=4.94, P=0.01$ for sardine and $F_{5,47}$ $=4.75, P=0.03$ for sprat). Further analyses on the relationship between $K_{n}$ and biochemical index were thus made by grouping data into two maturity categories: pre-spawning and spawning period versus resting period.

The relationships between $K_{n}$ and biochemical index values during non-reproductive period were highly variable displaying significant positive correlation in sardine (linear model, $n=25$, $P=0.002, R^{2}=0.41$ ), weaker significant positive correlation in anchovy (linear model, $\mathrm{n}=29$, $P=0.02, R^{2}=0.22$ ) but a lack of significant correlation for sprat (linear model, $\mathrm{n}=24, P=$ $0.10)$ (Fig. 3). During the reproductive period, the relationships between $K_{n}$ and biochemical index values were all non-significant (linear model, all $P>0.05$; Fig 3 ). 
The reproductive period for sardine and sprat induced lipid allocation from muscle to gonads (linear model, respectively, $\mathrm{n}=24, P<0.001, R^{2}=0.66$ for sardine and $\mathrm{n}=30, P<0.001, R^{2}=$ 0.44 for sprat) (Fig. 4). The anchovy did not exhibit any significant pattern (linear model, $P=$ 0.91) (Fig. 4).

\subsection{Repeatability of fatmeter measurement}

The repeatability $(r)$ of the fatmeter was 0.91 for anchovy, 0.96 for sardine and 0.77 for sprat (Table SI, Supplementary data). Independently of the species, the repeatability of the fatmeter measurements increased with fish size: $r=0.88$ ( $T L<105 \mathrm{~mm}, \mathrm{n}=17), 0.94$ (105 $\leq$ $\mathrm{TL}<115 \mathrm{~mm}, \mathrm{n}=68), 0.95$ (115 $\leq \mathrm{TL}<105 \mathrm{~mm}, \mathrm{n}=41), 0.97(\mathrm{TL} \geq 125 \mathrm{~mm}, \mathrm{n}=23$ ) (Table SII, Supplementary data).

\subsection{Impact of freezing on fatmeter measurements}

Fatmeter values from the two freezing durations were not significantly different for anchovy and sardine (ANOVA, respectively, $F_{3,38}=0.249, P=0.62, \mathrm{n}=42$ for anchovy and $F_{3,38}$ $=0.367, P=0.55, \mathrm{n}=42$ for sardine). Fatmeter values obtained from fresh fish and frozen fish were positively correlated for both species (linear model, $\mathrm{n}=42, P<0.001, R^{2}=0.66$ for anchovy; and $\mathrm{n}=42, P<0.001, R^{2}=0.90$ for sardine) (Fig. 5). The slope of the regression was significantly different from 1 for anchovy (respectively $0.73 \pm 0.09$ ), but not for sardine $(0.95 \pm 0.06)$.

On the contrary, a significant difference was detected for sprat between the regression slopes at 5 and 31 days of freezing (ANOVA, $F_{3,38}=15.12, P<0.001, \mathrm{n}=42$ ). Fatmeter values obtained from fresh and frozen sprats were positively correlated for both durations (linear model, $\mathrm{n}=21, P<0.001, R^{2}=0.53$ and $\mathrm{n}=21, P=0.041, R^{2}=0.19$ after 5 and 31 days of freezing) but the slopes differ between each other and from $1(1.99 \pm 0.43$ and $0.41 \pm 0.19$ respectively for 5 and 31 days).

\section{Discussion}

\subsection{Comparison of condition indices}

This study presents the first comparison of three different categories of condition indices (morphometric, bioenergetic and biochemical) applied to small pelagic fish (except for herring, Davidson and Marshall, 2010; McPherson et al., 2011). Commonly, condition is used as a measure of the energetic status of animals. Individuals in better condition are thus supposed to have greater energy reserves than individual in poorer condition, although energy reserves could reflect a whole range of different energy storage types. For example, fat content is only one component of energy reserves, and measuring physiological condition can also include quantification of protein (Lambert and Dutil, 1997; Sutton et al., 2000). Proteins are indeed used as an energy source when fat reserves are exhausted (Love, 1970; McCue, 2010), which results in a greater decrease in mass than changes in fat content. Morphometric condition indices that are based on mass and length, such as the relative condition index $\left(K_{n}\right)$ used here should thus vary with both fat and protein content. Therefore, these indices could reflect the shape (i.e the structure) of an individual rather than only its quantity of fat reserves (Stevenson and Woods, 2006). Bioenergetics and biochemical indices were used to estimate relative lipid content both indirectly and directly. Unsurprisingly, stronger correlations were thus found between the biochemical and the 
bioenergetics index than between these two and the $K_{n}$. These results also pointed out differences in correlation depending on the reproductive state of the fish.

During the non-reproductive period lipid storage is mainly located in muscle for clupeid species (Adams, 1999), while during the reproductive period-lipids are also allocated in tissues other than muscles, such as in particular in the developing gonads (lles, 1984; McBride et al., 2013). Taking into account the lipid content of muscle only during the nonreproductive period and both muscle and gonad during the reproductive period, the relative lipid content of the fish was precisely estimated. The high correlation between the biochemical index and the fatmeter measurements regardless of the species and period considered; has confirmed the ability of the fatmeter to reflect relative lipid content well. Previous studies have validated fatmeter calibrations to estimate muscle relative lipid content (Davidson and Marshall, 2010; McPherson et al., 2011). Here, calibrations to estimate the relative lipid content of the entire fish were used and validated, providing evidences that these two types of measurements may be used to monitor the relative lipid content of small pelagic fish. Moreover, the results obtained by comparing fatmeter and direct lipid estimations with the small sensor head were similar to the results in other studies conducted on larger fish (Davidson and Marshall, 2010; Klefoth et al., 2013; McPherson et al., 2011), underlining the equally good accuracy of the two types of sensors. The correlations between the biochemical and the relative condition index were weaker or absent. As previously established by McPherson et al. (2011) for herrings, these results highlighted that the $K_{n}$ does not measure exactly the same aspect of condition (especially during the reproductive period) as the bioenergetics and biochemical indices. Indeed, indices based on body weight, such as $K_{n}$, can obscure a seasonal pattern of fat reallocation between the different organs of the body (Fitzhugh et al., 2010). This may explain the lack of a relationship between $\mathrm{Kn}$ and direct estimators of lipids for spawning individuals as has been previously observed for other species (Brown and Murphy, 2004; Óskarsson, 2008; Sutton et al., 2000). Moreover, some authors have found a strong relationship between total muscle protein and body weight loss (Brown and Murphy, 2004; Dygert, 1990). This suggests that during the reproductive period, even if $K_{n}$ did not correlate with relative lipid content, it can be a useful condition index as it measures protein loss which indicates that the fish consumes muscle. Thus, during the reproductive period changes in $K_{n}$ might be less related to relative lipid content and reflect other processes, such as protein content changes, that define condition differently than just lipid content variations.

By looking at three different species of small pelagic fish, interspecific differences were exhibited in the strength of correlation between $K_{n}$ and the biochemical index and the fatmeter. Sardine, which is generally larger than the two others species, showed always the best correlation. Similar $R^{2}$ between $K_{n}$ and fatmeter measurements for herring (Vogt et al., 2002), which has a bigger size and weight than sardine. This could be due to the large variations in size and weight of sardine, well reflected by large variations of $K_{n}$. Also, size and weight measurements to the nearest millimeter and the nearest gram induced coarser measurements for anchovy and sprat, due to their smaller size and weight. This issue prevented from catching all the variability between individuals, limiting the accuracy by which reserve variations can be estimated using morphometric measurements. This could explain the lower $\mathrm{R}^{2}$ and the lack of relationship between $K_{n}$ and the biochemical index for sprat. For this reason, small-sized species need more precise morphometric measurements to catch reserve variability.

The $K_{n}$ and fatmeter values were also affected by the maturity stage, with an increasing condition with increasing maturity for anchovy and the inverse for sardine and sprat. Differences in reproductive period (i.e late spring/early summer for anchovy and winter for sardine and sprat, Palomera et al., 2007) may explain this contrasting patterns. In late 
spring/early summer, food is highly available and even if a part of the stored energy is allocated to gonad development, anchovy continues to feed and gain weight during reproduction, as already observed by Millán (1999). Similarly, lipids in the muscle are not depleted due to the abundance of food. On the contrary, planktonic food for sardine and sprat is at lower levels during winter, so that the energy allocation to the growing gonads induces a loss of weight and lipid depletion in muscles. As $K_{n}$ is based on total weight, this difference in reproductive period could explain the opposite observed effect of maturity stage on this index.

The fatmeter appeared as a good indirect index to evaluate the lipid content of the three species of small pelagic fish studied. The results for $K_{n}$ underlined that this index is a global indicator of condition, as it estimates both lipid and protein content rather than only lipids. The choice of an indirect index for further studies thus depends on the objectives of the study. As condition studies should define exactly what is really measured with indirect indices, further studies on anchovy, sardine and sprat are needed to determine if, as mentioned in Brown and Murphy (2004), $K_{n}$ may also be directly correlated with protein content or other health indicators.

\subsection{Repeatability of fatmeter measurements}

Because of the advantages of the fatmeter, the repeatability of this instrument was investigated, which was shown to be excellent. The difference between measurements realized on the same fish was small, with the highest repeatability for sardine and anchovy. A smaller repeatability value for sprat might originate from their small and thin body. As indicated in the Distell user manual (Kent, 1990), permittivity calculations performed by the fatmeter are less exact for individuals with body thickness inferior to 1.5 centimeters, which was regularly the case for sprat in the Gulf of Lions. In general, the larger the fish, the greater was the repeatability between measurements, which is in agreement with Kent et al., (1992). Thus, only one measurement on each fish side is enough to evaluate the total lipid content of a small pelagic fish, corresponding to less than one minute of handling time. However, duplicated readings are encouraged to minimize errors, mainly for smaller and thinner species.

\subsection{Freezing impact on fatmeter measurements}

For anchovy and sardine, all experiments on freezing duration pointed out a significant and strong correlation between fatmeter measurements performed on fresh fish and frozen fish. The absence of a significant effect of freezing on fish water content and thus on fatmeter measurements was already documented for other species (e.g. Vogt et al., 2002). Regost et al., (2004) showed that freezing over a timespan longer than one month does not change the water content of fish. This result allows dealing with up to one month frozen sardine and anchovy samples from research surveys or commercial catches. Except for 5-day frozen sprat wherefore an overestimation of lipid content was observed (i.e. a slope greater than 1), the regression slopes for the different freezing durations were always below 1 . This could be due to defrosting. Mørkøre et al., (2002) indeed showed that a part of the water contained inside the fish body of the rainbow trout moved towards the body surface during defrosting. This surface water accumulation may lead to an overestimation of the water content, which could exceed the minor effect of water loss due to freezing. Additionally, the presence of ice crystals after freezing can lead to an overestimation of the water content by disturbing microwave dispersal (Kent, 1990). Finally, besides the lower accuracy and repeatability of sprat measurement the significant change in the slope for sprat after freezing could also be explained by individuals being relatively fatter than sardine and anchovy and thus containing 
less water. Therefore, small changes in their water content could have a large effect on fat content measurements. Consequently, the use of freezing storage for sprat samples needs to be considered with more caution.

\section{Conclusion}

This study provided the basis to decide which techniques are best to investigate the condition of small pelagic fish in the Gulf of Lions (and probably more generally in the Mediterranean Sea). The fatmeter appears as a good option to quickly and accurately track the lipid content of small pelagic fish. Despite contrasting results, the relative condition index $\left(K_{n}\right)$ is not obsolete to track condition of small pelagic fish. This index indicates a correlation with the lipid content outside of the reproductive period but might also be sensitive to other parameters, such as fish protein content. The precision of morphometric measurements to the nearest gram and millimeter was found to be insufficient in the case of sprat, especially when compared to the other two species. Biochemical measurements of fat content are rarely practicable as routine analyses. For instance, lipid extraction is time consuming and samples need to be stored at low temperature $\left(-20^{\circ} \mathrm{C}\right.$ to $\left.-80^{\circ} \mathrm{C}\right)$, which is not always feasible on fishing boats. In contrast, the fatmeter has the advantages of being quick ( 1 minute per fish), portable, non-invasive, easy to use and giving the most reliable indirect index for small pelagic fish in our study. It can also be incorporated to field research and measurements can be taken on living fish (Cooke et al., 2005). This study showed that the fatmeter can be used properly on small size fish, such as anchovy, sardine and sprat. Furthermore, fatmeter measurements are repeatable and can be realized on frozen samples.

\section{Ackowledgements}

The authors are grateful to the captain and the crew of RV L'Europe", as well as all the scientists onboard for their assistance during PELMED surveys. PELMED surveys are cofinanced by Europe through the Data Collection Framework. We especially wish to thank all other fishing crews who contributed to the collection of samples at sea. We thank the two anonymous reviewers for their careful review of the manuscript and their excellent suggestions. This research was partly funded through the EcoPelGol project (Study of the Pelagic ecosystem in the Gulf of Lions), financed by France Filière Pêche (FFP). PB acknowledges doctoral fellowship support from the French Ministère de l'Education Nationale, de la Recherche et de la Technologie.

\section{References}

Adams, S.M., 1999. Ecological Role of Lipids in the Health and Success of Fish Populations, in: Arts, M.T., Wainman, B.C. (Eds.), Lipids in Freshwater Ecosystems. Springer New York, pp. 132-160.

Bervoets, L., Blust, R., 2003. Metal concentrations in water, sediment and gudgeon (Gobio gobio) from a pollution gradient: relationship with fish condition factor. Environmental Pollution 126, 9-19. doi:10.1016/S0269-7491(03)00173-8

Beveren, E.V., Bonhommeau, S., Fromentin, J.-M., Bigot, J.-L., Bourdeix, J.-H., Brosset, P., Roos, D., Saraux, C., 2014. Rapid changes in growth, condition, size and age of small pelagic fish in the Mediterranean. Mar Biol 1-14. doi:10.1007/s00227-0142463-1 
Bolger, T., Connolly, P.L., 1989. The selection of suitable indices for the measurement and analysis of fish condition. Journal of Fish Biology 34, 171-182. doi:10.1111/j.10958649.1989.tb03300.x

Brown, M.L., Murphy, B.R., 2004. Seasonal dynamics of direct and indirect condition indices in relation to energy allocation in largemouth bass Micropterus salmoides (Lacèpede). Ecology of Freshwater Fish 13, 23-36. doi:10.1111/j.0906-6691.2004.00031.x

Campañone, L.A., Salvadori, V.O., Mascheroni, R.H., 2001. Weight loss during freezing and storage of unpackaged foods. Journal of Food Engineering 47, 69-79. doi:10.1016/S0260-8774(00)00101-1

Cone, R.S., 1989. The Need to Reconsider the Use of Condition Indices in Fishery Science. Transactions of the American Fisheries Society 118, 510-514. doi:10.1577/15488659(1989)118<0511:TNTRTU>2.3.CO;2

Cooke, S.J., Crossin, G.T., Patterson, D.A., English, K.K., Hinch, S.G., Young, J.L., Alexander, R.F., Healey, M.C., Van Der Kraak, G., Farrell, A.P., 2005. Coupling noninvasive physiological assessments with telemetry to understand inter-individual variation in behaviour and survivorship of sockeye salmon: development and validation of a technique. Journal of Fish Biology 67, 1342-1358. doi:10.1111/j.10958649.2005.00830.x

Craig, J.F., 1977. The body composition of adult perch, Perca fluviatilis in Windermere, with reference to seasonal changes and reproduction. The Journal of Animal Ecology 617-632.

Craig, J.F., Kenley, M.J., Talling, J.F., 1978. Comparative estimations of the energy content of fish tissue from bomb calorimetry, wet oxidation and proximate analysis. Freshwater Biology 8, 585-590. doi:10.1111/j.1365-2427.1978.tb01480.x

Davidson, D., Marshall, C.T., 2010. Are morphometric indices accurate indicators of stored energy in herring Clupea harengus? Journal of Fish Biology 76, 913-929. doi:10.1111/j.1095-8649.2010.02546.x

Dygert, P.H., 1990. Seasonal Changes in Energy Content and Proximate Composition Associated with Somatic Growth and Reproduction in a Representative Age-Class of Female English Sole. Transactions of the American Fisheries Society 119, 791-801. doi:10.1577/1548-8659(1990)119<0791:SCIECA>2.3.CO;2

Fitzhugh, G.R., Wuenschel, M.J., McBride, R.S., 2010. Evaluation of bioelectrical impedance analysis (BIA) to measure condition and energy allocated to reproduction in marine fishes. J. Phys.: Conf. Ser. 224, 012137. doi:10.1088/1742-6596/224/1/012137

Folch, J., Lees, M., Stanley, G.H.S., 1957. A Simple Method for the Isolation and Purification of Total Lipides from Animal Tissues. J. Biol. Chem. 226, 497-509.

Green, A.J., 2001. Mass/length residuals: measures of body condition or generators of spurious results. Ecology 82, 1473-1483. doi:10.1890/00129658(2001)082[1473:MLRMOB]2.0.CO;2

ICES, 2008. Report of the Workshop on Small Pelagics (Sardina pilchardus, Engraulis encrasicolus) maturity stages (WKSPMAT), in: ICES CM 2008/ACOM. 10-14 November 2008, Mazara del Vallo, Italy, p. 82.

Iles, T.D., 1984. Allocation of resources to gonad and soma in Atlantic herring Clupea harengus L. Fish Reproduction, London: Academic Press.

Jakob, E.M., Marshall, S.D., Uetz, G.W., 1996. Estimating Fitness: A Comparison of Body Condition Indices. Oikos 77, 61-67. doi:10.2307/3545585

Kent, M., 1990. Hand-held instrument for fat/water determination in whole fish. Food Control 1, 47-53. doi:10.1016/0956-7135(90)90121-R

Kent, M., Lees, A., Christie, R.H., 1992. Seasonal variation in the calibration of a microwave fat: water content meter for fish flesh. International Journal of Food Science \& Technology 27, 137-143. doi:10.1111/j.1365-2621.1992.tb01189.x

Klefoth, T., Skov, C., Aarestrup, K., Arlinghaus, R., 2013. Reliability of non-lethal assessment methods of body composition and energetic status exemplified by applications to eel (Anguilla anguilla) and carp (Cyprinus carpio). Fisheries Research 146, 18-26. doi:10.1016/j.fishres.2013.03.010 
Lambert, Y., Dutil, J.-D., 1997. Can simple condition indices be used to monitor and quantify seasonal changes in the energy reserves of cod (Gadus morhua)? Can. J. Fish. Aquat. Sci. 54, 104-112. doi:10.1139/f96-149

Le Cren, E.D., 1951. The Length-Weight Relationship and Seasonal Cycle in Gonad Weight and Condition in the Perch (Perca fluviatilis). Journal of Animal Ecology 20, 201-219. doi: $10.2307 / 1540$

Lessells, C.M., Boag, P.T., 1987. Unrepeatable Repeatabilities: A Common Mistake. The Auk 104, 116-121. doi:10.2307/4087240

Lloret, J., Shulman, G., Love, R.M., 2013. Condition and Health Indicators of Exploited Marine Fishes. John Wiley \& Sons.

Love, R.M., 1970. The chemical biology of fishes. With a key to the chemical literature. $\mathrm{xv}+547 \mathrm{pp}$.

McBride, R.S., Somarakis, S., Fitzhugh, G.R., Albert, A., Yaragina, N.A., Wuenschel, M.J., Alonso-Fernández, A., Basilone, G., 2013. Energy acquisition and allocation to egg production in relation to fish reproductive strategies. Fish and Fisheries n/a-n/a. doi:10.1111/faf.12043

McCue, M.D., 2010. Starvation physiology: Reviewing the different strategies animals use to survive a common challenge. Comparative Biochemistry and Physiology Part A: Molecular \& Integrative Physiology 156, 1-18. doi:10.1016/j.cbpa.2010.01.002

McPherson, L.R., Slotte, A., Kvamme, C., Meier, S., Marshall, C.T., 2011. Inconsistencies in measurement of fish condition: a comparison of four indices of fat reserves for Atlantic herring (Clupea harengus). ICES J. Mar. Sci. 68, 52-60. doi:10.1093/icesjms/fsq148

Millán, M., 1999. Reproductive characteristics and condition status of anchovy Engraulis encrasicolus L. from the Bay of Cadiz (SW Spain). Fisheries Research 41, 73-86. doi:10.1016/S0165-7836(99)00010-7

Millar, J.S., Hickling, G.J., 1990. Fasting Endurance and the Evolution of Mammalian Body Size. Functional Ecology 4, 5-12. doi:10.2307/2389646

Mørkøre, T., Hansen, A. å., Unander, E., Einen, O., 2002. Composition, Liquid Leakage, and Mechanical Properties of Farmed Rainbow Trout: Variation Between Fillet Sections and the Impact of Ice and Frozen Storage. Journal of Food Science 67, 1933-1938. doi:10.1111/j.1365-2621.2002.tb08749.x

Nielsen, D., Hyldig, G., Nielsen, J., Nielsen, H.H., 2005. Lipid content in herring (Clupea harengus, L.) - influence of biological factors and comparison of different methods of analyses: solvent extraction, Fatmeter, NIR and NMR. LWT - Food Science and Technology 38, 537-548. doi:10.1016/j.Iwt.2004.07.010

Óskarsson, G.J., 2008. Variation in body condition, fat content and growth rate of Icelandic summer-spawning herring Clupea harengus L. Journal of Fish Biology 72, 26552676. doi:10.1111/j.1095-8649.2008.01886.x

Palomera, I., Olivar, M.P., Salat, J., Sabatés, A., Coll, M., García, A., Morales-Nin, B., 2007. Small pelagic fish in the NW Mediterranean Sea: An ecological review. Progress in Oceanography 74, 377-396. doi:10.1016/j.pocean.2007.04.012

Pangle, K.L., Sutton, T.M., 2005. Temporal changes in the relationship between condition indices and proximate composition of juvenile Coregonus artedi. Journal of Fish Biology 66, 1060-1072. doi:10.1111/j.0022-1112.2005.00660.x

Parrish, C.C., 1999. Determination of Total Lipid, Lipid Classes, and Fatty Acids in Aquatic Samples, in: Arts, M.T., Wainman, B.C. (Eds.), Lipids in Freshwater Ecosystems. Springer New York, pp. 4-20.

Regost, C., Jakobsen, J.V., Rørå, A.M.B., 2004. Flesh quality of raw and smoked fillets of Atlantic salmon as influenced by dietary oil sources and frozen storage. Food Research International 37, 259-271. doi:10.1016/j.foodres.2003.12.003

Schamber, J.L., Esler, D., Flint, P.L., 2009. Evaluating the validity of using unverified indices of body condition. Journal of Avian Biology 40, 49-56. doi:10.1111/j.1600048X.2008.04462.x 
Schulte-Hostedde, A.I., Millar, J.S., Hickling, G.J., 2001. Evaluating body condition in small mammals. Canadian Journal of Zoology 79, 1021-1029. doi:10.1139/cjz-79-6-1021

Schulte-Hostedde, A.I., Zinner, B., Millar, J.S., Hickling, G.J., 2005. RESTITUTION OF MASS-SIZE RESIDUALS: VALIDATING BODY CONDITION INDICES. Ecology 86, 155-163. doi:10.1890/04-0232

Simat, V., Bogdanović, T., 2012. Seasonal changes in proximate composition of anchovy (Engraulis encrasicolus, L.) from the central Adriatic. Acta Adriatica 53, 125-131.

Stevenson, R.D., Woods, W.A., 2006. Condition indices for conservation: new uses for evolving tools. Integr. Comp. Biol. 46, 1169-1190. doi:10.1093/icb/icl052

Sutton, S.G., Bult, T.P., Haedrich, R.L., 2000. Relationships among Fat Weight, Body Weight, Water Weight, and Condition Factors in Wild Atlantic Salmon Parr. Transactions of the American Fisheries Society 129, 527-538. doi:10.1577/15488659(2000)129<0527:RAFWBW>2.0.CO;2

Trudel, M., Tucker, S., Morris, J.F.T., Higgs, D.A., Welch, D.W., 2005. Indicators of Energetic Status in Juvenile Coho Salmon and Chinook Salmon. North American Journal of Fisheries Management 25, 374-390. doi:10.1577/M04-018.1

Vogt, A., Gormley, T.R., Downey, G., Somers, J., 2002. A Comparison of Selected Rapid Methods for Fat Measurement in Fresh Herring (Clupea harengus). Journal of Food Composition and Analysis 15, 205-215. doi:10.1006/jfca.2002.1049

Wilson, A.J., Nussey, D.H., 2010. What is individual quality? An evolutionary perspective. Trends in Ecology \& Evolution 25, 207-214. doi:10.1016/j.tree.2009.10.002

Zar, J.H., 1984. Biostatistical analysis, 2nd ed. Ed. Prentice Hall, USA. 
Table I. Total length $\left(L_{T}\right)$, weight $(\mathrm{W})$, relative condition index $\left(K_{n}\right)$, fatmeter measurements and direct biochemical relative lipid content estimation (latroscan lipid content) recorded in the Gulf of Lions for anchovy, sardine and sprat.

\begin{tabular}{lccc}
\hline \hline \multicolumn{1}{c}{ Variables } & Mean $\pm \mathrm{SD}$ & Range & Sample Size \\
\hline \hline Anchovy & & & \\
$L_{\mathrm{T}}(\mathrm{mm})$ & $114.89 \pm 10.57$ & $89-145$ & 499 \\
$\mathrm{~W}(\mathrm{~g})$ & $9.12 \pm 2.64$ & $4-19$ & 499 \\
$K_{n}$ & $0.97 \pm 0.09$ & $0.81-1.20$ & 499 \\
Fatmeter measurements (\%) & $6.72 \pm 1.69$ & $3.5-15.6$ & 499 \\
Iatroscan lipid content $(\%)$ & $1.82 \pm 1.32$ & $0.32-4.97$ & 59 \\
\hline & & & \\
Sardine & & & 488 \\
$L_{\mathrm{T}}(\mathrm{mm})$ & $125.51 \pm 12.58$ & $95-160$ & 488 \\
$\mathrm{~W}(\mathrm{~g})$ & $14.88 \pm 5.29$ & $5-35$ & 488 \\
$K_{n}$ & $1.04 \pm 0.126$ & $0.73-1.43$ & 55 \\
Fatmeter measurements $(\%)$ & $9.98 \pm 3.41$ & $4.9-23.1$ & \\
Iatroscan lipid content $(\%)$ & $2.41 \pm 1.65$ & $0.15-6.66$ & 187 \\
\hline Sprat & & & 187 \\
$L_{\mathrm{T}}(\mathrm{mm})$ & & & 187 \\
W (g) & & & \\
$K_{n}$ & $96.75 \pm 8.17$ & $75-115$ & 59 \\
Fatmeter measurements $(\%)$ & $18.67 \pm 6.37$ & $9.30-35.40$ & \\
Iatroscan lipid content $(\%)$ & $6.45 \pm 4.56$ & $1.96-21.89$ & \\
& & & \\
\hline
\end{tabular}




\section{Figures}

Figure. 1. Relationship between the relative condition index $(K n)$ and fatmeter values for anchovy $(y=0.017 x+0.86)$, sardine $(y=0.025 x+0.79)$ and sprat $(y=0.010 x+0.91)$. The lines indicate significant linear regressions.
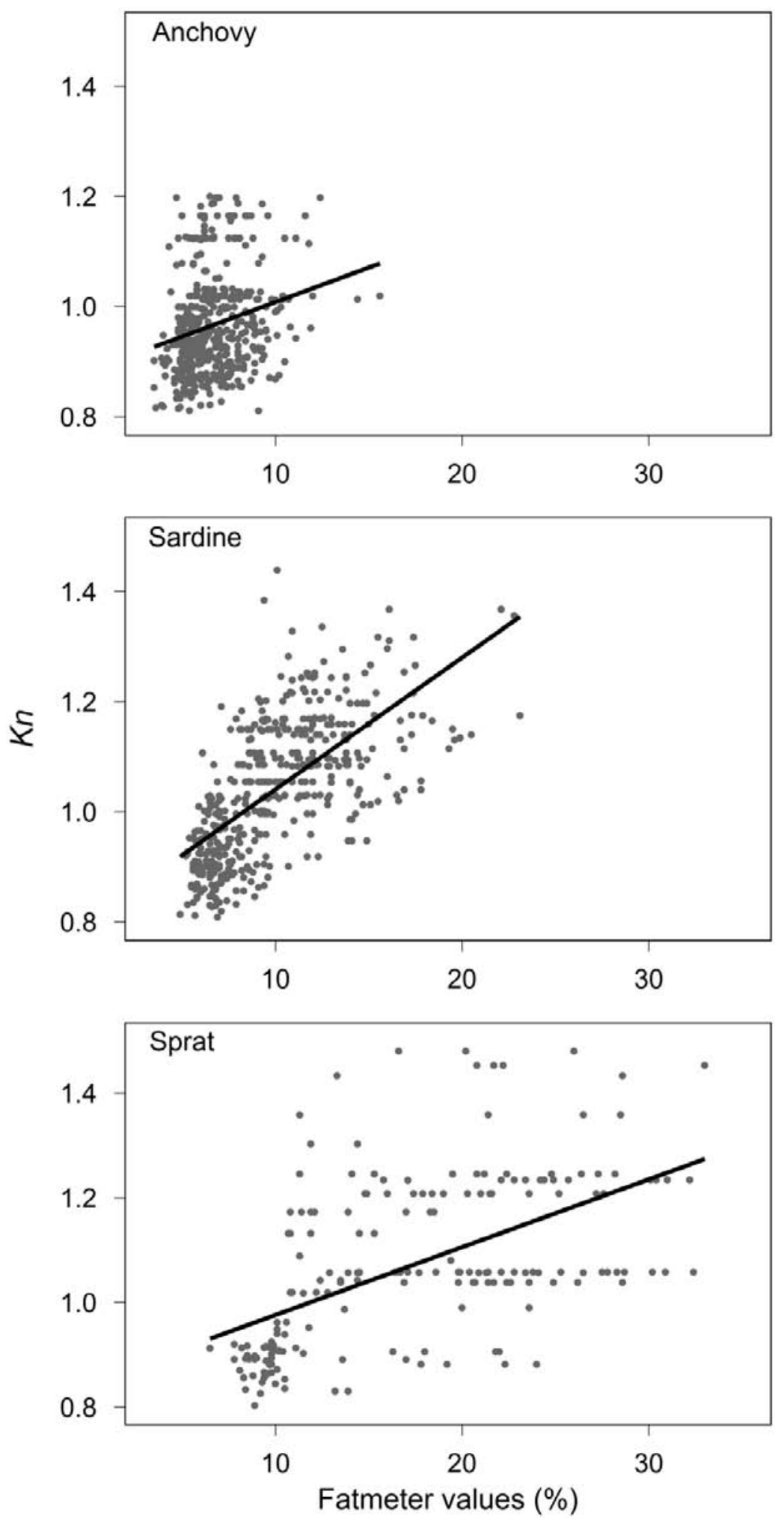
Figure. 2. Relationship between direct biochemical measurements of relative lipid content (latroscan) and fatmeter measurements for anchovy $(y=0.85 x+2.17)$, sardine $(y=0.56 x+$ $5.08)$ and sprat $(y=1.06 x+5.81)$. The lines indicate significant linear regressions.
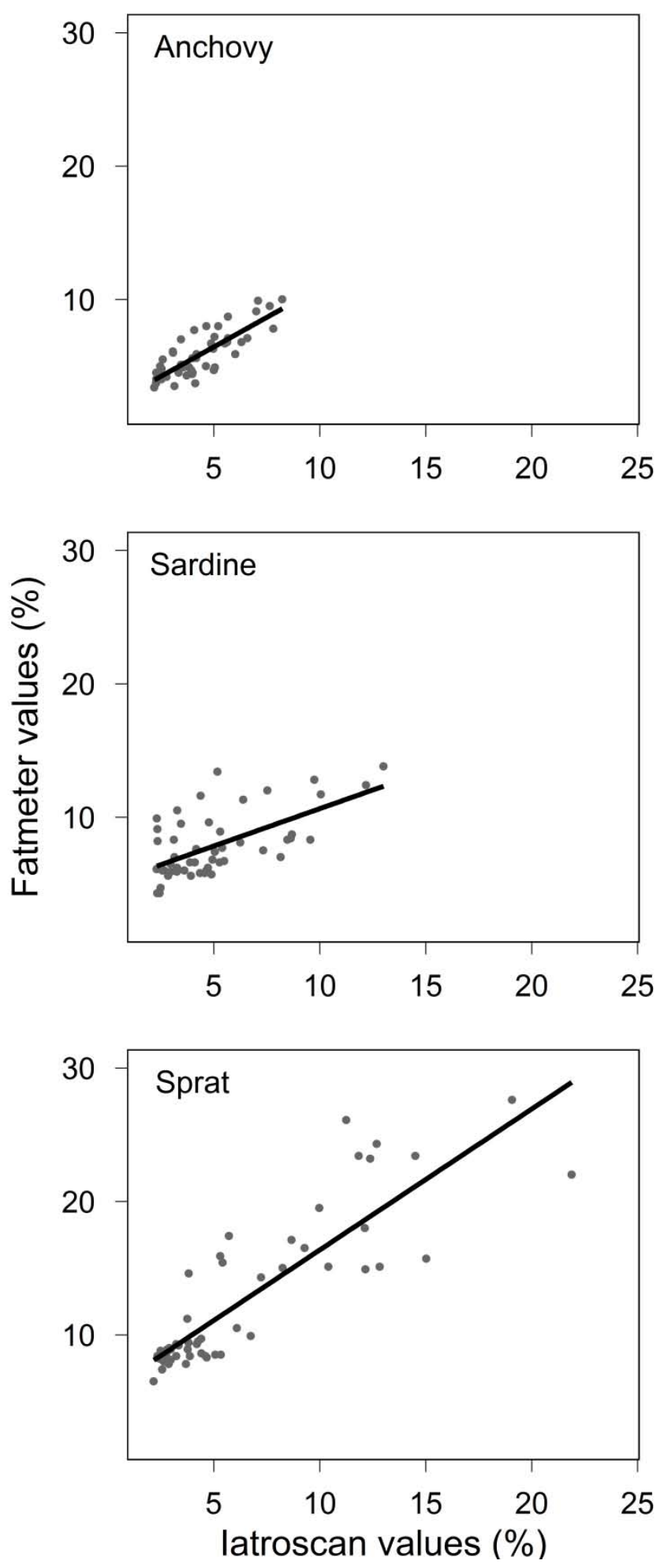
Figure. 3. Relationship between biochemical measurements of relative lipid content (latroscan) and the relative condition index $\left(K_{n}\right)$ depending on the reproductive status (resting reproductive period versus reproductive period) for anchovy (respectively $y=0.013 x+0.89$ and non-significant correlation for reproductive period), sardine (respectively $y=0.015 x+$ 1.09 and non-significant correlation for reproductive period), sprat (non-significant for the two periods). The lines indicate significant linear regressions.

No reproduction
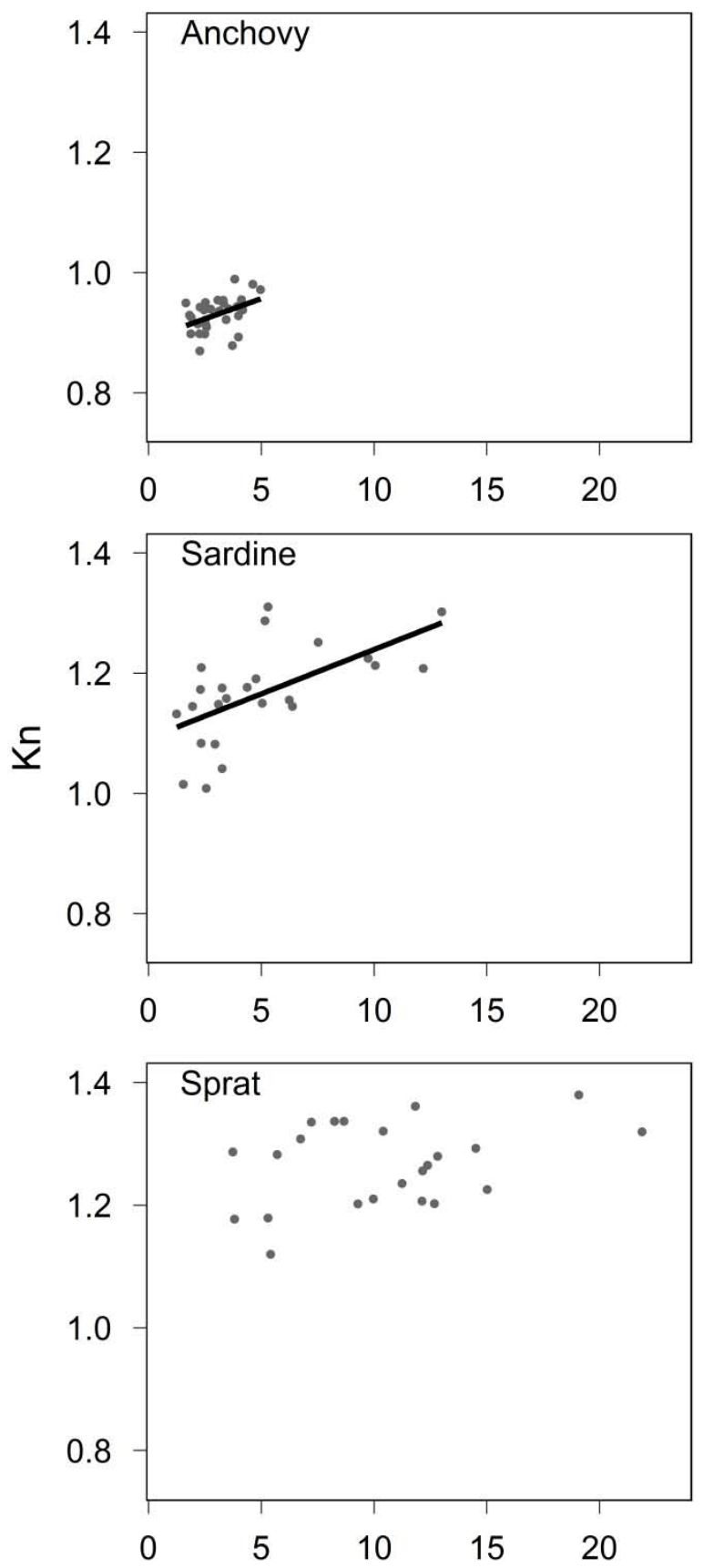
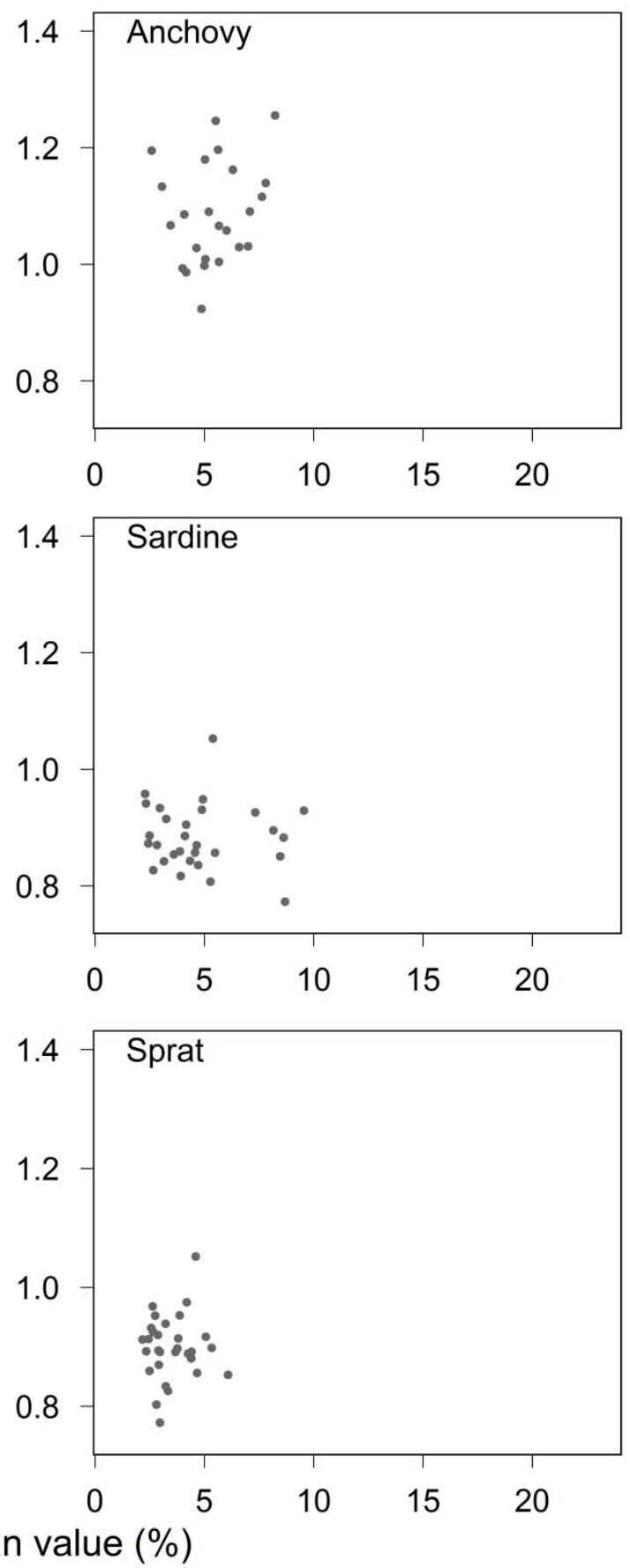
Figure 4. Relationship between biochemical measurements of muscle relative lipid content and gonad relative lipid content during the reproductive period for anchovy $(y=-0.14 x+$ 20.06), sardine $(y=-1.70 x+22.14)$ and sprat $(y=-1.03 x+19.02)$. The lines indicate significant linear regressions.
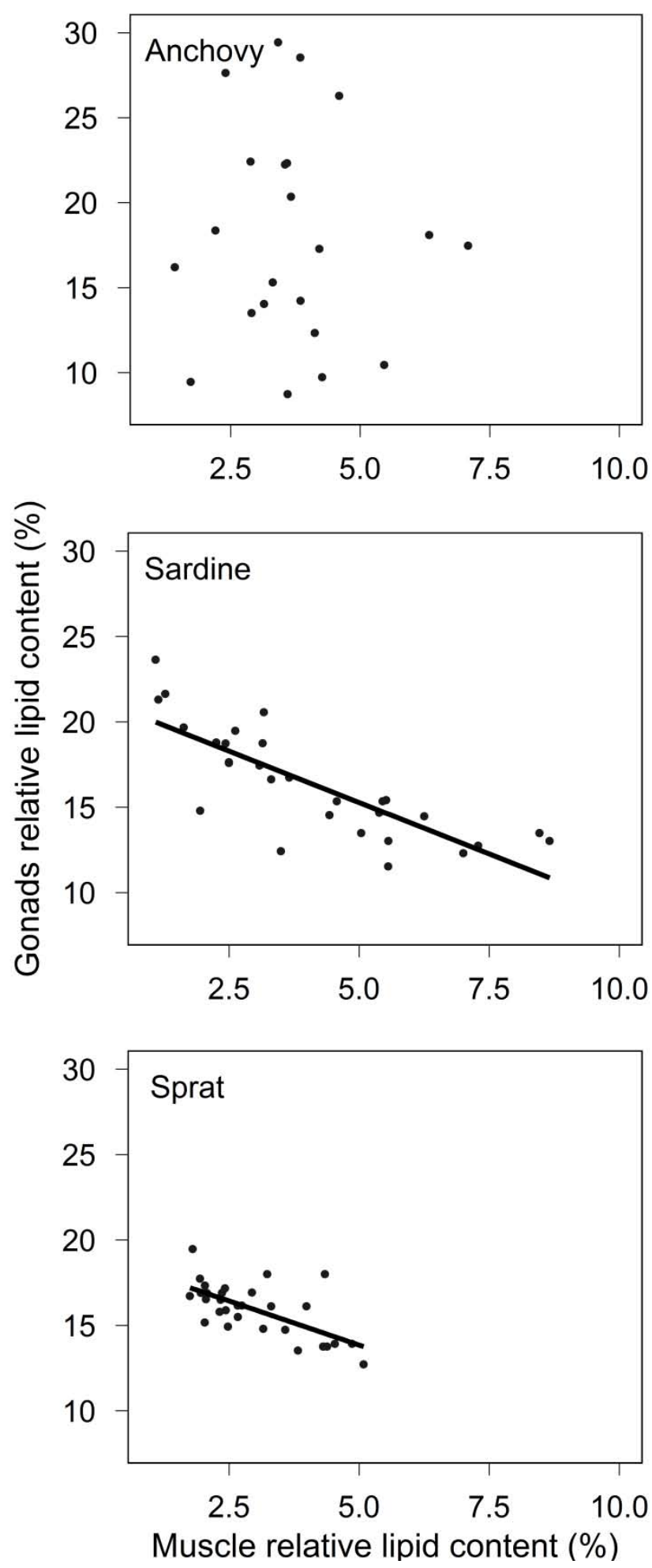
Figure. 5. Positive linear relationship between relative lipid content measured before and after 5 or 31 days of freezing for anchovy $(y=0.74 x+1.73)$, sardine $(y=0.95 x+0.47)$ and sprat (respectively $\mathrm{y}=1.99 x-8.78$ and $y=0.42 x+5.6926)$.
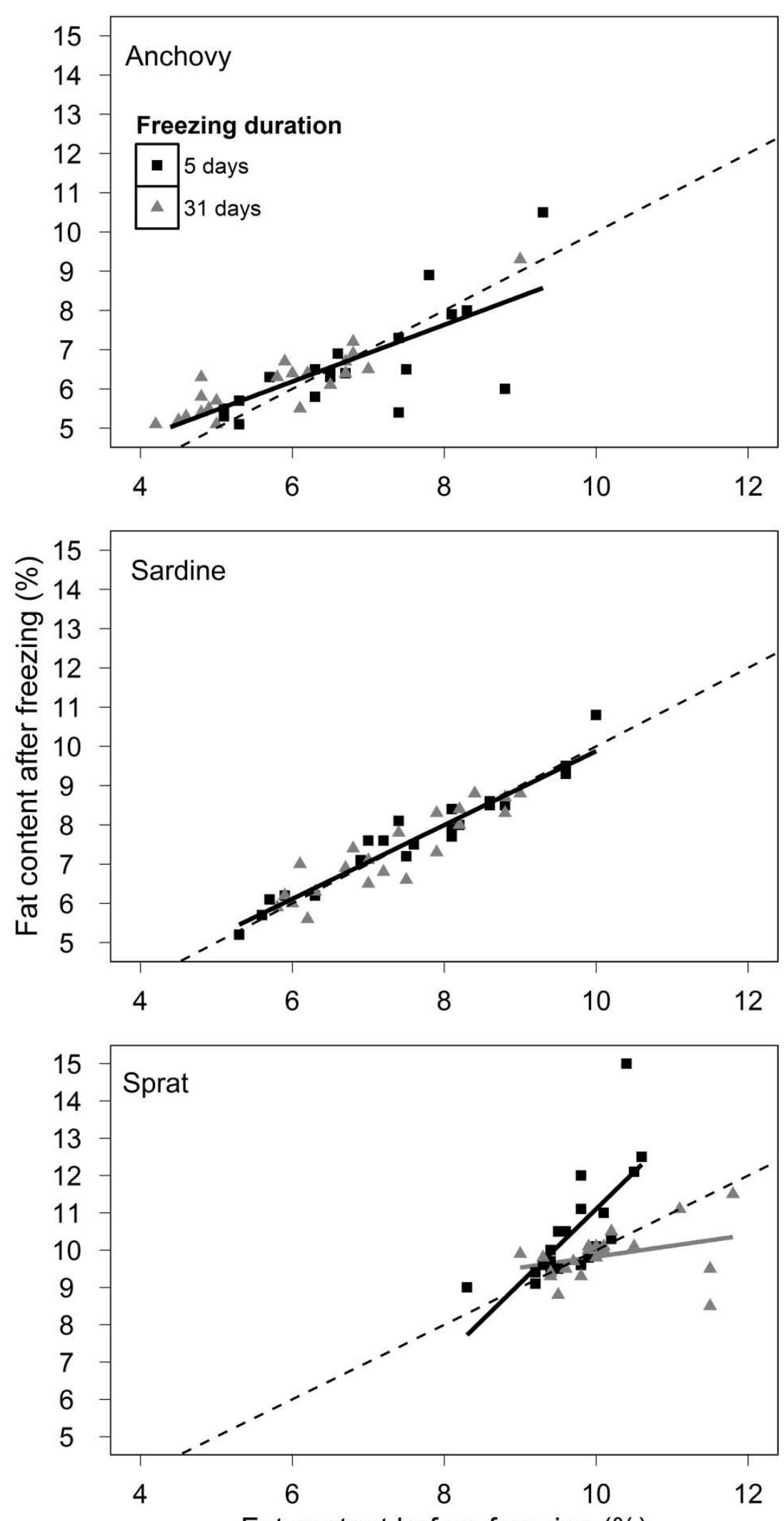

Fat content before freezing (\%) 